\title{
HUBUNGAN SANITASI LINGKUNGAN DENGAN KEJADIAN PENYAKIT ISPA DI PESANTREN IMMIM PUTRI KABUPATEN PANGKEP
}

\author{
Fitrianti $^{1}$ dan Muh.lkbal Arief $^{2}$ \\ 1,2,3 Jurusan Kesehatan Lingkungan Poltekkes Kemenkes Makassar \\ Fitriantitajuddin18@gmail.com
}

\begin{abstract}
The quality of the environment can affect human health. One of the factors that can affect the environmental quality is the presence of pollution in the environment. IMMIM Islamic boarding schools have a pretty good environment but some are still lacking such as environmental cleanliness, a lot of garbage scattered around the dormitory and lighting conditions that still need natural lighting/lighting This study aims to determine the relationship between environmental sanitation and the incidence of ARI in the IMMIM Putri Pesantren, Pangkep Regency. The research method is an analytic observation with a cross-sectional study approach, where data concerning the independent and dependent variables will be collected and measured at the same time with a sample size of 172 respondents. The results of the research conducted showed that there was a relationship between lighting and ARI disease $p=0.024<0.05$ and occupancy density $p=0.041<0.05$. Meanwhile, those not related to ARI disease were temperature $p=$ 0.061 , humidity $p=0.068$, and environmental cleanliness $p=0.296$ The conclusion of this study states that of the five variables, two variables are associated with ARI, namely lighting and occupancy density in IMMIM Islamic boarding schools. Therefore, it is recommended that counseling be carried out about the importance of maintaining good environmental sanitation conditions.
\end{abstract}

Keywords: Sanitation Environment, Acute Respiratory Tract Infection Disease Disease (ARI), Pesantren

\section{ABSTRAK}

Kualitas lingkungan hidup dapat mempengaruhi kesehatan manusia. Salah satu faktor yang dapat mempengaruhi kualitas lingkungan adalah adanya pencemaran dalam lingkungan. Pesantren IMMIM memiliki lingkungan yang cukup baik namun ada beberapa yang masih kurang seperti Kebersihan lingkungan yang banyak sampah berserakan di dalam Asrama dan keadaan pencahayaan yang masih butuh penerangan/pencahayaan alami. Penelitian ini bertujuan untuk mengetahui hubungan sanitasi lingkungan dengan kejadian penyakit ISPA yang di Pesantren IMMIM Putri Kabupaten Pangkep. Metode penelitian adalah observasi analitik dengan pendekatan crossectional study, dimana data yang menyangkut variabel bebas dan variabel terikat akan dikumpulkan dan diukur dalam waktu yang bersamaan dengan jumlah sampel sebanyak 172 responden. Hasil penelitian yang dilakukan menunjukkan bahwa ada hubungan antara pencahayaan dengan penyakit ISPA $\mathrm{p}=0.024<0.05$ dan kepadatan hunian $p=0.041<0.05$. Sedangkan yang tidak berhubungan dengan penyakit ISPA yaitu suhu $p=0.061$, kelembaban $p=0.068$ dan kebersihan lingkungan $\mathrm{p}=0.296$. Kesimpulan dari penelitian ini menyatakan bahwa dari lima variabel, terdapat dua variabel yang berhubungan dengan penyakit ISPA yaitu pencahayaan dan kepadatan hunian di Pesantren IMMIM. Olehkarena itu disarankan agar dilakukan penyuluhan tentang pentingnya menjaga kondisi sanitasi lingkungan dengan baik.

Kata Kunci :Sanitasi Lingkungan, Penyakit ISPA, Pesantren

\section{PENDAHULUAN}

Kondisi lingkungan pesantren sangat berpengaruh pada proses belajar-mengajar siswa. Seperti lingkungan asrama/kamarnya. Kondisi lingkungan yang dimaksud ialah seperti kebersihan lingkungan, kepadatan penghuni, ventilasi, dan sebagainya. Kondisi lingkungan di Pesantren IMMIM Putri tidak memenuhi syarat seperti dari segi jendela yang banyak debu, jumlah penghuni sebanyak 8 hingga 10 orang per kamar, sampah yang berserakan dimana-mana.

Kualitas Fisik Udara dalam Ruang Rumah adalah nilai parameter yang mengindikasikan kondisi fisik udara dalam rumah seperti kelembaban,pencahayaan, suhu, dan partikulat

Adapun yang meliputi bagian dari sanitasi lingkungan adalah penyediaan air bersih, makanan-minuman, limbah, sampah, vector, dan lain-lain. oleh karena itu kondisi sanitasi lingkungan sangat berpengaruh terhadap kesehatan manusia. Sangat banyak penyakit yang disebabkan oleh kualitas lingkungan seperti, ISPA, DBD, Malaria, Dermatitis, dan sebagainya.

ISPA juga merupakan masalah kesehatan yang penting karena menjadi penyebab pertama kematian di Negara berkembang. Setiap tahun ada dua juta kematian yang disebabkan oleh ISPA. WHO memperkirakan insidensi ISPA di Negara berkembang $0,29 \%$ (151 juta jiwa). ISPA menempati urutan pertama penyakit yang diderita oleh bayi dan balita di Indonesia. Prevalensi ISPA di Indonesia adalah 25,5\% dengan morbiditas pneumonia pada bayi $2,2 \%$ dan balita $3 \%$, sedangkan mortalitas pada bayi $23,8 \%$ dan balitta 15,5\%. (Marni, 2014)

$\mathrm{Di}$ Indonesia kasus ISPA selalu menempati urutan pertama penyebab kematian bayi. Sebanyak $36,4 \%$ kematian bayi pada tahun $2008(32,1 \%)$ pada tahun 2009 (18,2\%) pada tahun $2010(38,8 \%)$, disebabkan karena ISPA. Selain itu, ISPA sering berada pada daftar sepuluh penyakit terbanyak penderitanya di rumah sakit. Berdasarkan data dari P2 program ISPA tahun 
Jurnal Sulolipu : Media Komunikasi Sivitas Akademika dan Masyarakat

Vol. 20 No.12020

e-issn : 2622-6960, p-issn : 0854-624X

2009, cakupan penderita ISPA melampaui target $13,4 \%$, hasil yang diperoleh 18.749 penderita. Survei mortalitas yang dilakukan Subdit ISPA tahun 2010 menempatkan ISPA sebagai penyebab terbesar kematian bayi di Indonesia dengan persentase $22,30 \%$ dari seluruh kematian balita (Depkes RI, 2012).

Masalah kesehatan yang dialami dunia saat ini semakin berat, dimana masalah-masalah penyakit menular belum terselesaikan kemudian muncul penyakit tidak menular. Berdasarkan data yang diperoleh di Dinas Kesehatan Provinsi Sulawesi Selatan bahwa tingkat kasus ISPA di Sulawesi selatan tahun 2017 ialah sebanyak 169.373 kasus untuk golongan semua umur, sedangkan tahun 2018 sedangkan pada tahun 2018 ialah 305.433 kasus.

Berdasarkan data yang diperoleh dari Dinas Kesehatan Provinsi Sulawesi Selatan bahwa cakupan ISPA di Kabupaten Pangkep pada tahun 2015 yaitu 5812, tahun 2016 yaitu 2477, tahun 2017 yaitu 4755, dan tahun 2018 yaitu sebanyak 10.515 kasus

Berdasarkan data penyakit yang diperoleh di Poskestren (Pos Kesehatan Pesantren) di IMMIM penyakit ISPA merupakan salah satu jenis penyakit tertinggi, pada tahun 2016 terdapat 22 kasus ISPA, tahun 2017 terdapat 16 kasus, sedangkan pada tahun 2018 terdapat 15 kasus. Selain itu, hasil wawancara dengan petugas poskestren bahwa ada juga siswi yang terkena ISPA dan gejala ISPA dikarenakan selama tinggal di Pesantren.

\section{METODE}

Waktu:

1. Tahap Persiapan, meliputi pengumpulan data primer dan

2. Sekunder yang berlangsung pada bulan Desember 2018

3. Tahap pelaksanaan, meliputi survey, observasi dan pengukuran yang berlangsung pada bulan Mei-Juni 2019

\section{Metode penelitian}

Metode yang digunakan adalah observasi analitik dengan pendekatan crossectional study, dimana data yang menyangkut variabel bebas dan variabel terikat akan dikumpulkan dan diteliti dalam waktu yang bersamaan. Lokasi penelitian yang dilakukan bertempat di Pesantren IMMIM PUTRI Kabupaten Pangkep. Sedangjan jumlah sampel yang digunakan dalam penelitian ini adalah 172 dari jumlah populasi sebanyak 300 siswa, jumlah sampel tersebut diperoleh menggunakan rumus sloving. Selain itu, instrument yang digunakan adalah kuesioner dan lembar observasi, dan data diolah menggunakan uji statistic chi-square.

\section{HASIL}

Tabel 1

Distribusi Responden Berdasarkan Umur di Pesantren IMMIM Putri Kabupaten Pangkep

\begin{tabular}{ccc}
\hline Umur & Jumlah & $\%$ \\
\hline Nov-15 & 100 & 58 \\
\hline $16-20$ & 72 & 42 \\
\hline Total & 172 & 100 \\
\hline
\end{tabular}

Sumber: Data Primer

Tabel 2

Distribusi Responden Berdasarkan Pendidikan di Pesantren IMMIM Putri Kabupaten Pangkep

\begin{tabular}{ccc|}
$\begin{array}{c}\text { Kriteria } \\
\text { Pendidikan }\end{array}$ & Jumlah & $\%$ \\
\hline SMP & 114 & 66 \\
\hline SMA & 58 & 34 \\
\hline Total & 172 & 100 \\
\hline
\end{tabular}

Tabel 3

Hubungan Pencahayaan dengan Kejadian Penyakit ISPA Di Pesantren IMMIM Putri Kabupaten Pangkep

\begin{tabular}{|c|c|c|c|c|c|c|c|c|}
\hline \multirow[b]{2}{*}{$\begin{array}{c}\text { Pencahayaa } \\
n\end{array}$} & \multicolumn{4}{|c|}{ Kejadian ISPA } & \multirow[b]{2}{*}{$\begin{array}{c}\text { Tota } \\
\text { । }\end{array}$} & \multirow[b]{2}{*}{$\%$} & \multirow[b]{2}{*}{ Total } & \multirow[b]{2}{*}{$\begin{array}{c}\text { Statisti } \\
\text { C }\end{array}$} \\
\hline & ISPA & $\%$ & $\begin{array}{c}\text { Tida } \\
k \\
\text { ISPA }\end{array}$ & $\%$ & & & & \\
\hline $\begin{array}{c}\text { Tidak } \\
\text { memenuhi } \\
\text { syarat }\end{array}$ & 20 & 12 & 42 & 24 & 62 & 36 & \multirow{2}{*}{$\begin{array}{c}100 \\
\%\end{array}$} & $\begin{array}{c}X^{2}= \\
5.078\end{array}$ \\
\hline $\begin{array}{l}\text { Memenuhi } \\
\text { syarat }\end{array}$ & 19 & 11 & 91 & 53 & 110 & 64 & & $\begin{array}{c}p= \\
0.024\end{array}$ \\
\hline Total & 39 & 23 & 133 & 77 & 172 & & & \\
\hline
\end{tabular}

Sumber: Data Primer

Tabel 4

Hubungan Kepadatan Hunian Dengan Kejadian Penyakit ISPA Di Pesantren IMMIM Putri Kabupaten Pangkep

\begin{tabular}{|c|c|c|c|c|c|c|c|c|}
\hline \multirow{2}{*}{$\begin{array}{l}\text { Kepadatan } \\
\text { Hunian }\end{array}$} & \multicolumn{4}{|c|}{ Kejadian ISPA } & \multirow{2}{*}{ Total } & \multirow{2}{*}{$\%$} & \multirow{2}{*}{ Total } & \multirow{2}{*}{ Statistic } \\
\hline & ISPA & $\%$ & $\begin{array}{l}\text { Tidak } \\
\text { ISPA }\end{array}$ & $\%$ & & & & \\
\hline $\begin{array}{c}\text { Tidak } \\
\text { memenuhi } \\
\text { syarat }\end{array}$ & 26 & 15 & 64 & 37 & 90 & 52 & $100 \%$ & 4.158 \\
\hline $\begin{array}{l}\text { Memenuhi } \\
\text { syarat }\end{array}$ & 13 & 8 & 69 & 40 & 82 & 48 & & $\begin{array}{c}p= \\
0.041\end{array}$ \\
\hline Total & 39 & 23 & 133 & 77 & 172 & & & \\
\hline
\end{tabular}

Sumber: Data Primer 
Jurnal Sulolipu : Media Komunikasi Sivitas Akademika dan Masyarakat

Vol. 20 No.12020

e-issn : 2622-6960, p-issn : 0854-624X

Tabel 5

Hubungan Suhu dengan Kejadian Penyakit ISPA Di Pesantren IMMIM Putri Kabupaten Pangkep

\begin{tabular}{|c|c|c|c|c|c|c|c|c|}
\hline \multirow[b]{2}{*}{ Suhu } & \multicolumn{4}{|c|}{ Kejadian ISPA } & \multirow[b]{2}{*}{ Total } & \multirow[b]{2}{*}{$\%$} & \multirow[b]{2}{*}{ Total } & \multirow[b]{2}{*}{ Statistic } \\
\hline & ISPA & $\%$ & $\begin{array}{l}\text { Tidak } \\
\text { ISPA }\end{array}$ & $\%$ & & & & \\
\hline $\begin{array}{c}\text { Tidak } \\
\text { memenuhi } \\
\text { syarat }\end{array}$ & 16 & 9 & 34 & 20 & 50 & 29 & \multirow{2}{*}{$100 \%$} & $\begin{array}{c}X^{2}= \\
3.496\end{array}$ \\
\hline $\begin{array}{l}\text { Memenuhi } \\
\text { syarat }\end{array}$ & 23 & 13 & 99 & 58 & 122 & 71 & & $\begin{array}{c}p= \\
0,061\end{array}$ \\
\hline Total & 39 & 23 & 133 & 77 & 172 & & & \\
\hline
\end{tabular}

Tabel 6

Hubungan Kelembaban Dengan Kejadian Penyakit ISPA Di Pesantren IMMIM Putri Kabupaten Pangkep

\begin{tabular}{|c|c|c|c|c|c|c|c|c|}
\hline \multirow[b]{2}{*}{$\underset{n}{\text { Kelembaba }}$} & \multicolumn{4}{|c|}{ Kejadian ISPA } & \multirow[b]{2}{*}{$\begin{array}{c}\text { Tota } \\
\text { I }\end{array}$} & \multirow[b]{2}{*}{$\%$} & \multirow[b]{2}{*}{ Total } & \multirow[b]{2}{*}{ Statistic } \\
\hline & $\begin{array}{c}\text { ISP } \\
\mathrm{A}\end{array}$ & $\%$ & $\begin{array}{c}\text { Tida } \\
k \\
\text { ISPA } \\
\end{array}$ & $\%$ & & & & \\
\hline $\begin{array}{c}\text { Tidak } \\
\text { memenuhi } \\
\text { syarat }\end{array}$ & 3 & $\begin{array}{l}1 \\
6\end{array}$ & 27 & 2 & 30 & $\begin{array}{l}1 \\
7\end{array}$ & \multirow{2}{*}{$\begin{array}{c}100 \\
\%\end{array}$} & \multirow{2}{*}{$\begin{array}{c}\mathrm{X}^{2}=3.32 \\
9 \\
\mathrm{p}=0,068\end{array}$} \\
\hline $\begin{array}{c}\text { Memenuhi } \\
\text { syarat }\end{array}$ & 36 & $\begin{array}{l}2 \\
1 \\
\end{array}$ & 106 & $\begin{array}{l}6 \\
2 \\
\end{array}$ & 142 & $\begin{array}{l}8 \\
3 \\
\end{array}$ & & \\
\hline Total & 39 & $\begin{array}{l}2 \\
3\end{array}$ & 133 & $\begin{array}{l}7 \\
7\end{array}$ & 172 & & & \\
\hline
\end{tabular}

Sumber: Data Primer

Tabel 7

Hubungan Kebersihan Lingkungan Dengan Kejadian Penyakit ISPA Di Pesantren IMMIM Putri Kabupaten Pangkep

\begin{tabular}{|c|c|c|c|c|c|c|c|c|}
\hline \multirow[b]{3}{*}{$\begin{array}{l}\text { Kebersihan } \\
\text { Lingkungan }\end{array}$} & \multirow{2}{*}{\multicolumn{4}{|c|}{$\begin{array}{c}\text { Pangkep } \\
\text { Kejadian ISPA }\end{array}$}} & \multirow[b]{3}{*}{ Total } & \multirow[b]{3}{*}{$\%$} & \multirow[b]{3}{*}{ Total } & \multirow[b]{3}{*}{ Statistic } \\
\hline & & & & & & & & \\
\hline & ISPA & $\%$ & $\begin{array}{l}\text { Tidak } \\
\text { ISPA }\end{array}$ & $\%$ & & & & \\
\hline $\begin{array}{c}\text { Tidak } \\
\text { memenuhi } \\
\text { syarat } \\
\end{array}$ & 18 & 10 & 74 & 43 & 92 & 53 & \multirow[t]{2}{*}{$100 \%$} & $\begin{array}{c}X^{2}= \\
1.091 \\
p=\end{array}$ \\
\hline $\begin{array}{c}\text { Memenuhi } \\
\text { syarat }\end{array}$ & 21 & 12 & 59 & 34 & 80 & 47 & & 0.296 \\
\hline Total & 39 & 23 & 133 & 77 & 172 & & & \\
\hline
\end{tabular}

\section{PEMBAHASAN}

\section{Hubungan Pencahayaan dengan kejadian penyakit ISPA}

Berdasarkan olah data yang dilakukan menggunakan SPSS uji chi square diperoleh hasil $\mathrm{X}^{2}$ Hit $=5.078>\mathrm{X}^{2} \mathrm{Hit}_{\mathrm{H}}=3.841(\mathrm{p}=0.024$ $<\alpha=0.05$, maka ada hubungan yang signifikan antara pencahayaan dengan kejadian penyakit ISPA di Pesantren IMMIM.

Hal ini sejalan dengan penelitian yang dilakukan oleh Nur Qamarina (2009) di Panti Asuhan Anak Harapan Kota Samarinda yang menyatakan bahwa ada hubungan antara pencahayaan ruang tidur dengan penyakit ISPA dengan nilai $p=0.046<\alpha=0.05$

Pencahayaan yang terdapat di kamar asrama pesantren berupa pencahayaan alami dan buatan, dalam hal ini pencahayaan alami diperoleh dari adanya ventilasi namun ukuran ventilasinya saja kecil sehingga menyebabkan pencahayaan alami yang masuk hanya sedikit dan tidak memenuhi syarat, juga karena ruangan/kamar yang ditempati jarang sekali bahkan tidak pernah membuka jendelanya dan menyebabkan udara dalam ruangan tidak tersiklus dengan baik dan dapat mengakibatkan perkembangbiakan mikroorganisme. Sedangkan pencahayaan buatan diperoleh dari lampu yang ada dalam kamar, jadi setiap hari baik siang maupun malam lampu dalam kamar tetap dinyalakan untuk memperoleh pencahayaan yang cukup, karena jika lampu tidak dinyalakan saat siang hari maka pencahayaan yang ada didalam kamar akan cukup gelap. Selain itu jika disesuaikan dengan pengukuran yang dilakukan tentang pengukuran pencahayaan dengan menggunakan alat lux meter maka diperoleh 54-58 lux sedangkan menurut Permenkes RI/NO. 1007/MENKES/V/2011 bahwa pencahayaan dalam ruang minimal $60 l u x$ dan apabila tidak sesuai dengan standar yang ditentukan maka dinyatakan tidak memenuhi syarat.

Oleh karena itu pencahayaan yang terdapat di Pesantren IMMIM Putri ini dinyatakan tidak memenuhi syarat sesuai uji chi square, observasi, dan Permenkes yang digunakan.Hal inilah yang menunjukkan bahwa terjadinya penyakit ISPA di Pesantren IMMIM Putri Kabupaten Pangkep ini ada hubungan dengan pencahayaan yang ada.

\section{Hubungan Kepadatan Hunian dengan Kejadian Penyakit ISPA}

Hasil kepadatan hunian yang diperoleh di Pesantren IMMIM berdasarkan uji statistic yaitu $\mathrm{X}^{2}$ Hit $=4.158>\mathrm{X}^{2}$ Hit $=3.841$ dan $\mathrm{p}=0.041<\alpha=0.05$. hal ini menunjukkan bahwa ada hubungan antara tingkat kepadatan hunian terhadap kejadian penyakit ISPA di Pesantren IMMIM Putri.

Hal ini sejalan dengan penelitian yang dilakukan oleh Nindy Dewi Astuty (2016) tentang hubungan perilaku santri dan kondisi lingkungan fisik dengan kejadian ISPA di pondok pesantren Assalafi Al Fithrah Surabaya pada variable kepadatan penghuni yang menyatakan bahwa ada hubungan yang bermakna antara kepadatan hunian dengan kejadian penyakit ISPA dengan hasil uji chi square $p=0.049<\alpha 0.05$. 
Jurnal Sulolipu : Media Komunikasi Sivitas Akademika dan Masyarakat

Vol. 20 No.12020

e-issn : 2622-6960, p-issn : 0854-624X

Pesantren IMMIM Putri memiliki 17 kamar.Adapun penghuni tiap kamar 17-20 org/kamar.Kepadatan penghuni rumah/ruangan yang melebihi syarat kesehatan pada dasarnya mengakibatkan aktivitas penghuni dikamar merasa terganggu, dapat mengakibatkan terjadinya polusi udara, menghalangi atau mengganggu proses pertukaran udara bersih dengan kotor tidak berjalan lancar sehingga berpotensi mengganggu pernapasan seseorang. Selain itu luas bangunan yang tidak sesuai dengan jumlah penghuninya akan mengakibatkan mudahnya penghuni ruangankamar tersebut terkena penyakit menular, seperti penyakit ISPA. Faktor-faktor pemicu meningkatnya pertumbuhan mikroba didalam ruangan salah satunya adalah kepadatan hunian.

Kepadatan di dalam kamar yang tidak sesuai dengan standar akan meningkatkan suhu ruangan yang disebabkan oleh pengeluaran panas badan yang akan meningkatkan kelembaban akibat uap air dari pernapasan tersebut. Dengan demikian semakin banyak jumlah penghuni ruangan tidur maka akan semakin cepat udara ruangan mengalami pencemaran. Menurut

Kepmenkes 829/MENKES/SK/VII/1999, kepadatan hunian dikatakan memenuhi syarat apanila luas ruangan tidur $8 \mathrm{~m}^{2}$ untuk 2 orang. Bangunan yang sempit dan tidak sesuai dengan jumlah penghuninya akan mempunyai dampak kurangnya oksigen dalam ruangan sehingga daya tahan tubuh penghuninya menurun.

\section{Hubungan Suhu dengan Kejadian Penyakit ISPA}

Hasil olah data yang dilakukan dengan menggunakan SPSS uji chi square diperoleh $\mathrm{X}^{2} \mathrm{Hit}_{\mathrm{it}}=3.496<\mathrm{X}^{2} \mathrm{Hit}_{\mathrm{it}}=3.841(\mathrm{p}=$ $0.061>\alpha=0.05$, hal ini menunjukkan bahwa tidak ada hubungan signifikan antara suhu dan kejadian penyakit ISPA di Pesantren IMMIM Putri.

Hal ini sejalan dengan penelitian yang dilakukan oleh Nindy Dewi Astuty (2016) tentang hubungan suhu ruang dengan kejadian penyakit ISPA di pondok pesantren Assalafi Al Fithrah kota Surabaya yang menyatakan bahwa tidak ada hubungan antara suhu dengan kejadian penyakit ISPA dengan hasil yang diperoleh $p=0.078<\alpha 0.05$

Temperatur suhu yang ada di Pesantren memang sudah cukup bagus karena berdasarkan pengukuran yang dilakukan rata-rata suhu kamar memenuhi syarat yaitu sekitar $29^{\circ} \mathrm{C}-31^{\circ} \mathrm{C}$ hal ini sesuai yang dinyatakan dalam Permenkes No 1077 Tahun 2011 tentang Pedoman Penyehatan Udara Dalam Ruang Rumah bahwa syarat suhu dalam ruangan berkisar $18^{\circ} \mathrm{C}-30^{\circ} \mathrm{C}$. selain itu sekitar lingkungan Asrama juga terdapat beberapa pohon, hal ini semakin membuat suhu di asrama semakin adem atau tidak begitu panas.

Salah satu bakteri penyebab ISPA adalah Streptococcus pneumonia dimana bakteri ini paling baik tumbuh pada suhu $37^{\circ} \mathrm{C}$, dan gejala yang paling umum yang ditimbulkan ialah demam, batuk, dan takipneu. Sedangkan suhu yang ada di Pesantren tidak sampai $37^{\circ} \mathrm{C}$.

\section{Hubungan Kelembaban dengan Kejadian Penyakit ISPA}

Hasil kelembaban dengan kejadian penyakit ISPA adalah $\mathrm{X}^{2}$ Hit $=3.329<\mathrm{X}^{2} \mathrm{Hit}=$ $3.841(\mathrm{p}=0.068>\alpha=0.05$ ini menunjukkan bahwa tidak ada hubungan yang signifikan antara kelembaban dengan kejadian penyakit ISPA di Pesantren IMMIM Putri.

Hal ini sejalan dengan penelitian Lara Sati 2013, dkk tentang hubungan kualitas udara dalam ruangan asrama santriwati dengan kejadian ISPA di Pondok Pesantren Raudhatul Ulum dan Al-Ittifaqiah Islamic Boarding School In Ogan Ilir On 2015 di Universitas Sriwijaya yang menyatakan bahwa tidak ada hubungan antara kelembaban dengan kejadian ISPA dengan hasil uji chi square $p=0,170>0,05$. Hasil pengukuran kelembaban yang diperoleh di Pesantren IMMIM Putri ialah rata-rata kamar memiliki kelembaban $50 \%-56 \%$. Ini sesuai dengan persyaratan Permenkes Rl/No. 1007/MENKES/V/2011 bahwa kelembaban dalam ruangan berkisar $40 \%-60 \%$

\section{Hubungan Kebersihan Lingkungan Dengan Kejadian Penyakit ISPA}

Hasil kebersihan lingkungan yang diperoleh di Pesantren IMMIM menggunakan uji statistic yaitu $X^{2}$ Hit $=1.091<X^{2}$ Hit $=3.841$ dan $\mathrm{p}=0.296>\alpha=0.05$ hal ini menunjukkan bahwa tidak ada hubungan antara kebersihan lingkungan dengan kejadian Penyakit ISPA di Pesantren IMMIM Putri

Hal ini sejalan dengan penelitian yang dilakukan oleh Lara Sati (2013) tentang 
Jurnal Sulolipu : Media Komunikasi Sivitas Akademika dan Masyarakat

Vol. 20 No.12020

e-issn : 2622-6960, p-issn : 0854-624X

hubungan perilaku membersihkan ruangan dengan kejadian ISPA di Pesantren Raudhatul Ulum dan Al-Ittifaqiah Islamic Boarding School In Ogan Ilir On 2015 di Universitas dengan pvalue $0.389>\alpha 0.05$

Menurut Depkes RI tahun 1993, persyaratan kesehatan kamar/ruang pondok pesantren ialah:

1. Selalu dalam keadaan bersih dan mudah diberishkan, tersedia tempat sampah sesuai jenis samphanya serta tersedia fasilitas sanitasi sesuai kebutuhan.

2. Di dalam lingkungan pondok pesantren baik didalam maupun diluar ruangan harus mendapat pencahayaan yang memadai

3. Pada lingkungan pesantren baik didalam maupun diluar ruangan harus mendapat cahaya dengan intensitas berdasarkan fungsinya.

Berdasarkan hasil pemantauan yang dilakukan ternyata tidak hanya penyakit ISPA saja yang terjadi di pesantren tetapi juga penyakit-penyakit lainnya seperti dermatitis, scabies, febris, dan penyakit-penyakit lainnya.Pentingnya menjaga kebersihan lingkungan sangatlah utama karena banyak penyakit yang bisa timbul apabila lingkungan yang kita tempati tidak dalam keadaan baik.

\section{KESIMPULAN}

a. Ada hubungan antara pencahayaan dengan kejadian ISPA di Pesantren

b. Ada hubungan antara kepadatan hunian dengan kejadian ISPA di Pesantren

c. Tidak ada hubungan antara suhu dengan kejadian ISPA di Pesantren

d. Tidak ada hubungan antara kelembaban dengan kejadian ISPA di Pesantren

e. Tidak ada hubungan kebersihan lingkungan dengan kejadian ISPA di Pesantren

\section{SARAN}

a. Bagi Pemerintah

Agar meningkatkan kerjasama antara masyarakat/Pesantren IMMIM untuk meningkatkan upaya kesadaran akan pentingnya menjaga kondisi lingkungan.

b. Bagi Pesantren IMMIM

Sebaiknya dilakukan penyuluhan mengenai pentingnya menjaga kondisi lingkungan karena kondisi lingkungan dapat mempengaruhi timbulnya suatu penyakit, seperti penyakit ISPA.

c. Bagi Instansi/Poltekkes Kesehatan Makassar Sebaiknya fasilitas seperti alat-alat laboratorium dicukupkan, agar penelitian yang dilakukan dapat berjalan dengan baik dan lebih efisien.

\section{DAFTAR PUSTAKA}

Apriningsih. 2012. Kesehatan Lingkungan Anak. Jakarta: EGC

Budiman Chandra. 2007. Pengantar Kesehatan Lingkungan. Jakarta: EGC

Depkes R.I. 1993. Persyaratan Kesehatan Lingkungan Tempat-tempat Umum. Jakarta: PPM \& PLP.

Depkes R.I. 2012. Profil Kesehatan Indonesia Tahun 2012. (Online) http://www.depkes.go.id/resources/download/pusdatin/profil-kesehatan-indonesia/profilkesehatan-indonesia-2012.pdf (Diakses pada 10 Januari 2019)

Lara Sati. 2013. Hubungan Kualitas Udara Dalam Ruangan Asrama Santriwati dengan Kejadian ISPA di Pesantren Raudhatul Ulum dan Al Ittifaqiah (Online) http://ejournal.fkm.unsri.ac.id/index.php/jikm/article/view/200 (Diakes Pada 19 Juni 2019)

Marni. 2014. Asuhan Keperawatan Pada Anak Dengan Gangguan Pernapasan. Yogyakarta: Gosyen Publishing

Nindy Dewi Astuty.2016. Hubungan Lingkungan Fisik dengan Kejadian ISPA di Pesantren (Online) https://www.google.com/search?q=jurnal+penelitian+tentang+hubungan+lingkungan+fisik+deng an+kejadian+ispa+di+pesantren\&oq=jurnal+penelitian+tentang+hubungan+lingkungan+fisik+de ngan+kejadian+ispa+di+pesantren\&aqs=chrome. $.69 i 57.82700 j 0 j 7 \&$ sourceid $=$ chrome\&ie=UTF -8 (Diakses Pada 19 Juni 2019) 
Jurnal Sulolipu : Media Komunikasi Sivitas Akademika dan Masyarakat

Vol. 20 No.12020

e-issn : 2622-6960, p-issn : 0854-624X

Republik Indonesia. Kepmenkes R.I Nomor 829 Tahun 1999. Tentang Persyaratan Kesehatan Perumahan (Online) https://peraturan.bkpm.go.id/jdih/userfiles/batang/KEPMENKES_829_1999.pdf (Diakses Pada 10 Januari)

Republik Indonesia. Permenkes R.I. 2011. Tentang Pedoman Penyehatan Udara Dalam Ruang Rumah. (Online)

http://www.tungkuindonesia.org/images/downloads/Peraturan_Menteri_Kesehatan_No.1077.pdf (Diakses Pada 10 Januari 2019)

Dinata Arda (2018). Kesehatan Lingkungan. Yogyakarta: Nuha Medika.

Inayah dkk. (2012). Sanitasi Pemukiman. Makassar.Kementerian Kesehatan RI, Politeknik Kesehatan Makassar Jurusan Kesehatan Lingkungan. 